\title{
SUBSISTEMA DE INFORMAÇÃO DE CUSTOS NO SETOR PÚBLICO: PROPOSTA DE UM MODELO DE MENSURAÇÃO E ACUMULAÇÃO COM BASE NO REGIME DE COMPETÊNCIA
}

\author{
Elisangela Santos Fernandes ${ }^{1}$
} João Eudes Bezerra Filho ${ }^{2}$

\begin{abstract}
Resumo: A presente pesquisa se dedica à proposição de diretrizes para implantação de Subsistema de Mensuração e Acumulação de Informação de Custos no Setor Público (SMAIC-SP), integrado com os princípios da Contabilidade e com as Normas Brasileiras de Contabilidade aplicadas ao setor público, em especial a NBC TSP 16.11. O modelo tende a ser de abrangência geral, podendo ser aplicado nas três esferas de governo: União, Estados e Municípios, de forma a contribuir com os gestores públicos no processo de implantação do Subsistema de Informação de Custos no Setor Público (SICSP). A metodologia consiste em pesquisa dedutiva, com abordagem qualitativa e técnica de pesquisa bibliográfica. Os resultados apontam que a estrutura proposta do SMAIC-SP pode auxiliar no processo de identificação dos custos dos serviços públicos, por objeto de custo, em atendimento aos princípios e normas de contabilidade aplicados ao setor público, e, por conseguinte contribuir com as entidades públicas no processo de implantação do SICSP. Observou-se ainda, que as informações de custos geradas pelo SMAIC-SP podem contribuir para o processo de prestação de contas, tomada de decisão e instrumentalização do controle social.
\end{abstract}

Palavras-chave: Contabilidade Pública; Gestão Pública; Custos no Setor Público.

${ }^{1}$ E-mail: elisantosfernandes@gmail.com - Fucape Business School

${ }^{2}$ E-mail: jeudes@uol.com.br - Fucape Business School

- DOI: http://dx.doi.org/10.14392/asaa.2016090205

- Trabalho apresentado na Sessão Especial do IX Congresso Anpcont. Artigo recebido em: 14/07/2015. Revisões requeridas em: 04/04/2016. Aceito em: 19/08/2016. 


\section{THE INFORMATION SUBSYSTEM OF COSTS IN THE PUBLIC SECTOR: PROPOSAL FOR A MODEL OF MEASUREMENT AND COMBINATION BASED ON THE ACCRUAL BASIS}

Abstract: This research is dedicated to propose guidelines for implementation of the Subsystem of Measurement and Accumulation of Cost Information in the Public Sector (SMAIC-SP), integrated with the principles of Accounting and with the Brazilian Accounting Standards applied to the public sector, especially the NBC TSP 16.11. The model tends to be expansive; it can be applied in the three spheres of government:Union, states and municipalities, in order to contribute with the public managers in the implementation process of Subsystem of Cost Information in the Public Sector (SICSP). The methodology consists of deductive research, with a qualitative approach and bibliographic research methods. The results show that the proposed structure of SMAIC-SP can assist in the identification process of the costs of public services, by cost object, in response to the accounting principles and standards applied to the public sector, and, therefore contribute to public entities in the SICSP implementation process. It was also noted, that the costs information generated by SMAIC-SP can contribute to the accountability procedures, decision making and orchestration of social control.

Keywords: Public Accounting; Public Management; Costs in the Public Sector. 


\section{INTRODUÇÃO}

Nomats o Brasil, a adoção do Sistema de Custos pelas entidades do setor público tem previsão legal desde a edição da Lei n ${ }^{\circ} .4 .320 / 64$, tendo sido, também, exigido por outros normativos posteriores, dentre os quais o Decreto-Lei no. 200/1967, a Emenda Constitucional 19/1998 que introduziu na Constituição Federal de 1988 a obrigatoriedade de obediência ao princípio da eficiência pelas entidades da Administração Pública - e a Lei de Responsabilidade Fiscal (Lei Complementar nº. 101/2000).

Entretanto, apesar de os normativos legais já estabelecerem a necessidade de adoção de Sistema de Custos no setor público, desde 1964, segundo Machado e Holanda (2010, p. 793), "o fato é que a administração pública, até 2010 (seja o Executivo, Legislativo ou Judiciário), não utilizava Sistema de Custos, salvo por iniciativas isoladas de alguns órgãos".

Ressaltaram ainda Machado e Holanda (2010, p. 799) a necessidade de adoção do regime de competência no setor público, o qual permite que o registro, processamento e evidenciação das informações sejam realizados com base no fato gerador contábil, isto é, independentemente da execução orçamentária, desta forma contribuindo com o processo de geração de informação de custos por competência.

Buscando suprir essa lacuna, o Conselho Federal de Contabilidade (CFC), dando continuidade ao processo de mudanças das práticas contábeis no setor público no Brasil, iniciado com o objetivo tanto de fortalecer o enfoque patrimonial da contabilidade aplicada ao setor público, quanto de promover a convergência às normas internacionais de contabilidade, editou em novembro de 2011 a Resolução no. 1366/11.

A Resolução 1366/11, a qual editou a NBC TSP 16.11 dispôs sobre a implantação de Subsistema de Informação de Custos no Setor Público (SICSP), a qual, conjugada com a Portaria nº. 634/2013, editada pela Secretaria do Tesouro Nacional (STN), em novembro de 2013, reforçam a necessidade de implantação do referido subsistema por todas as entidades do setor público por força das definições contidas nas Leis $n^{\circ} .4 .320 / 64$ e nº. 101/00 quanto a questão.

Segundo Machado e Holanda (2010), a falta de cumprimento às determinações legais pelas entidades no setor público, no que tange à adoção de um Sistema de Custos, pelo menos até 2010, está relacionada à ausência de sistema e metodologia adequada para utilização por todo o governo federal.

Nesse sentido, o modelo de Sistema de Custos adotado pelo Governo Federal, implantado em 2010, foi desenvolvido a partir dos estudos realizados por Holanda (2002) e Machado (2002) e utiliza como fonte de alimentação a informação orçamentária, realizando os respectivos "ajustes contábeis" propostos no modelo, de modo a tornar esta equivalente a informação de custos.

Entretanto, conforme disposto pela NBC TSP 16.11 (2012, p. 51)“na geração de informação de custo, é obrigatória a adoção dos princípios de contabilidade em especial o de competência, devendo ser realizados os ajustes necessários quando algum registro for efetuado de forma diferente".

Nesse contexto, a partir do diagnóstico da situação-problema que se reflete na necessidade de desenvolvimento de um conjunto de diretrizes e metodologias para implantação de um Subsistema de Mensuração e Acumulação de Informaç̧̃es de Custos dos Serviços no Setor Público (SMAIC-SP), em conformidade com as disposições contidas na NBC TSP 16.11, surge a seguinte questão de pesquisa: 
Como estruturar um Subsistema de Mensuração e Acumulação de Informações de Custos dos Serviços Públicos que atenda aos Princípios Contábeis e às orientações contidas nas Normas Brasileiras de Contabilidade Aplicadas ao Setor Público, em especial a NBC TSP 16.11?

Para tanto, o objetivo geral da presente pesquisa foi desenvolver um conjunto conceitual de diretrizes, de abrangência geral, que auxilie na implantação de um Subsistema de Mensuração e Acumulação de Informação de Custos no Setor Público - SMAIC-SP, em conformidade com a NBC TSP 16.11 e, por conseguinte contribuir com o processo de tomada de decisão, prestação de contas e instrumentalização do controle social.

No que diz respeito à técnica de pesquisa aplicada para desenvolvimento da referida pesquisa, fez-se uso da bibliográfica, onde o objetivo foi realizar levantamento do máximo de informações e/ou conhecimentos que possibilitaram refletir e agregar soluções ao problema proposto, tendo-se desenvolvido as seguintes etapas: identificação e localização das fontes e obtenção do material, leitura do material, tomada de apontamentos, análise e interpretação dos apontamentos levantados, proposta de subsistema de mensuração e acumulação de informação de custos no setor público, apresentação de um exemplo simulado e, finalmente, apresentação das conclusões finais.

\section{REVISÃO NORMATIVA DA CONTABILIDADE APLICADA AO SETOR PÚBLICO NO BRASIL}

Os registros contábeis no setor público, estão previstos a partir da vinda do Rei D. João VI para o Brasil, que editou o Alvará de 28 de junho de 1808, estabelecendo a criação do Erário Régio e do Conselho da Fazenda, tendo ordenado que a escrituração fosse realizada por meio das partidas dobradas.

Em 1940, foi editado o Decreto Lei no. 2.416, que aprovou a codificação das normas financeiras para os Estados e Municípios e estabeleceu as premissas a serem observadas no processo de elaboração e execução do orçamento, bem como da contabilidade patrimonial e industrial.

Vinte e quatro anos depois, ou seja, em 1964, identifica-se como marco do processo regulatório das Finanças Públicas no Brasil a edição da Lei nº. 4.320/64, tendo instituído normas de direito financeiro a serem observadas pelos entes públicos da administração pública (direta e indireta), ou seja, União, Estados, Municípios e Distrito Federal, para elaboração, execução e controle dos orçamentos, bem como dos registros contábeis patrimoniais.

Entretanto, apesar de a Lei 4.320/64 dispor em seu texto de um Capítulo específico que trata sobre Contabilidade Patrimonial, “[...] na prática, desde o advento desta adota-se como momento do reconhecimento da receita e da despesa na Contabilidade do setor público o regime misto [...]" (Cruvinel \& Lima, 2011, p. 75).

Para Cruvinel e Lima (2011, p. 75), isto acontece em virtude da interpretação equivocada do artigo 35 da Lei no. 4.320/64, ao estabelecer "que pertencem ao exercício financeiro as receitas nele arrecadadas (I) e as despesas nele legalmente empenhadas".

Nesse contexto, o processo de mudanças das práticas contábeis no setor público no Brasil, o qual tem como objetivos principais reforçar o enfoque patrimonial da contabilidade e promover o processo de convergência às práticas internacionais, foi fortalecido com a edição da Resolução CFC no. 1.111/2007, tendo criado o apêndice II à Resolução CFC no. 750/93, ambas do Conselho Federal de Contabilidade, dando interpretação aos princípios contábeis sob a perspectiva do setor público. 
Em 25 de agosto de 2008, foi publicada pelo Ministério da Fazenda a Portaria 184/2008, determinando à STN, o desenvolvimento de ações no sentido de promover a convergência das práticas contábeis brasileiras às Normas Internacionais, tendo iniciado, a partir daí, a composição de grupos técnicos visando às publicações de manuais e instruções para adoção da chamada "nova contabilidade pública" do país.

Também em 2008, dando continuidade às supracitadas mudanças, foram publicadas pelo CFC, 10 (dez) Normas Brasileiras de Contabilidade aplicadas ao Setor Público - (NBCASP), com o objetivo de normatizar os procedimentos a serem utilizados pelas entidades do setor público para registro, processamento e evidenciação das informações geradas pela contabilidade.

Em novembro de 2011, foi publicada pelo CFC a 11 a Norma Brasileira de Contabilidade Aplicada ao Setor Público através da Resolução $n^{\circ}$ 1366/11, a qual trata sobre Subsistema de Informação de Custos do Setor Público, tema objeto desta pesquisa. Nesse contexto de mudanças das práticas contábeis, a STN buscando orientar o processo de implantação dos novos procedimentos contábeis, bem como definir cronogramas e prazos para implantação das NBCASP, editou, em 2014, a 6ª edição do Manual de Contabilidade Aplicada ao Setor Público (MCASP), que estabeleceu prazos para adoção dos procedimentos contábeis tratados no citado MCASP, dentre os quais, a implantação do Subsistema de Custos do Setor Público (SICSP), requerendo atenção especial, considerando que a determinação para implantação do citado subsistema encontra lastro legal desde a edição da Lei Federal nº. 4.320/64 e Lei Complementar n 101 de 2000.

\section{A NECESSIDADE DE INFORMAÇÕES DE CUSTOS NO SETOR PÚBLICO}

Em se tratando do setor público, onde o objetivo principal não é a geração de resultado, mas sim o bom desempenho e gerenciamento dos recursos públicos visando prestação de serviços ao cidadão, a aplicação de um sistema de custos teria a finalidade principal de aferição de eficiência e instrumento de gestão dos serviços prestados (Reis, Ribeiro \& Slomski, 2005).

Salienta-se que apesar de a legislação no setor público já estabelecer a obrigatoriedade de adoção do sistema de custos pelas entidades públicas desde 1964, com o advento da edição da Lei 4.320, conforme tratado Machado e Holanda (2010), a falta de cumprimento às determinações legais pelas entidades no setor público, no que tange à adoção de um Sistema de Custos, estava relacionada à ausência de sistema e metodologia adequada para utilização por todo o governo federal.

Em estudo realizado por Silva (1996) sobre a adoção do sistema de custo no setor público, apontou que a implantação de uma contabilidade de custos no setor governamental envolve duas fases, a de implantação e a de desenvolvimento. No modelo proposto por Silva (1996, p. 64), "para implantação do Sistema de Custos é fundamental a interligação entre os diversos sistemas de apoio administrativo, financeiro e contábil". Considerando as características do setor público, Silva (1996, p. 61) sugere que os órgãos públicos "devem adotar na acumulação o custo total, pleno ou por absorção que preconiza a determinação dos custos diretos [...] e a adição de determinada taxa que representa a distribuição das despesas indiretas ou gerais".

O modelo proposto por Silva (1996) utiliza a informação advinda da execução orçamentária e financeira para alimentação do sistema de custeamento. Machado (2002) buscou explicitar um con- 
junto de diretrizes para nortear a construção de um sistema de informação de custo aplicável ao setor público, propondo um modelo de sistema de informação de custo para o setor público, que deve ser "[...] integrado conceitual e sistematicamente aos subsistemas de orçamento público e de contabilidade governamental", fazendo uso do método de custeio direto, "o qual aloca todos os custos - fixos e variáveis - diretamente aos objetos de custo sem qualquer tipo de rateio ou apropriação" (Machado, 2002, p. 211).

No que tange ao sistema de acumulação, o modelo proposto por Machado (2002, p. 208) prevê que, "em primeiro lugar, os custos dos projetos sejam acumulados por ordem e que os custos das atividades sejam acumulados por processo".

Quanto às informações de custos, Machado (2002, p. 207) propôs estabelecer uma correspondência entre os conceitos de contabilidade governamental e a da contabilidade empresarial, tendo concluído que as despesas liquidadas orçamentárias equivalem ao conceito de gasto e podem ser consideradas como valores aproximados dos custos dos produtos ou serviços prestados em determinado período e, portanto, necessitam passar por "ajustes contábeis" para que correspondam a informação de custo.

Nesse contexto, para que a afirmação de que as despesas liquidadas classificadas como despesas de custeio são custos de algum bem ou serviço seja verdadeira, é necessário à realização de ajustes nas informações geradas pelo subsistema orçamentário (Machado, 2002). O modelo desenvolvido por Machado (2002) serviu de base para o desenvolvimento do Sistema de Custos do Governo Federal, o qual está utilizando a despesa orçamentária liquidada como base para alimentação do sistema de informação de custos, respeitados os devidos ajustes contábeis previstos no modelo.

Fernandes e Slomski $(2011$, p. 1) investigaram a "importância do desenvolvimento de métodos de identificação, planejamento e controle gerencial dos gastos da administração pública brasileira sob a forma de 'gestão de custos'". Os resultados do estudo apontaram que, apesar de $81,2 \%$ das entidades pesquisadas indicarem que utilizam um sistema de custeio, o desenvolvimento do processo de custos na administração pública brasileira ainda é um assunto nascente, mas em ampla ascensão (Fernandes \& Slomski, 2011).

Quanto a isso, Fernandes e Slomski (2011, p. 14) afirmaram que o Poder Público:

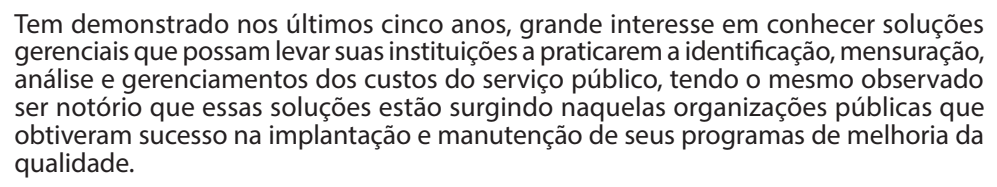

Já na pesquisa realizada por Rezende, Cunha e Bevilacqua (2010), buscou-se examinar em que medida as principais experiências internacionais de adoção de métodos contábeis para aferir os custos governamentais oferecem lições importantes para as mudanças necessárias no caso brasileiro. Entre os países selecionados para fins da apreciação na pesquisa, foram considerados os interesses específicos do Brasil, tendo sido incluídos os pioneiros, como a Austrália, a Nova Zelândia e o Reino Unido, que adotaram o regime de competência no bojo de reformas abrangentes em todo o processo orçamentário. Além disso, outros países citados foram os EUA e Canadá, por terem, igualmente, implantado a contabilidade de competência no setor público sem estender esse regime a todo o orçamento" (Rezende, Cunha \& Bevilacqua, 2010).

Em sua pesquisa, os autores apresentaram algumas razões da importância de adotar um sistema de informações de custos na administração pública, conforme Quadro 1: 
Quadro 1: Importância em se adotar um sistema de informações sobre custos na Administração Pública. Há várias razões para a adoção de procedimentos que permitam aferir os custos do governo, mas a mais importante delas é que sem que se
conheçam os custos das políticas e programas executados pelo setor público é impossível saber se o dinheiro do contribuinte está sendo bem utilizado.

Para saber se os recursos oriundos do pagamento de impostos estão sendo bem utilizados é necessário comparar os custos com os resultados para responder às seguintes perguntas: um dado resultado (por exemplo, a melhoria no desempenho escolar) está sendo obtido ao menor custo possível, ou existe um grande desperdício? Alternativamente, com os mesmos recursos aplicados seria possível conseguir resultados melhores?

Portanto, o conhecimento dos custos é indispensável para que o governo tome providências para melhorar a qualidade do gasto público e para que a população se mobilize para pressioná-lo a tomar as providências necessárias. Melhorando a qualidade do gasto e reduzindo desperdícios é possível baixar os impostos sem comprometer os serviços essenciais e os programas sociais.

Isso chama atenção para outra razão importante para a adoção de um sistema que gere informações sobre os custos do governo: a transparência do gasto público e a possibilidade de um melhor controle democrático sobre as prioridades no uso dos recursos públicos e a qualidade dos serviços prestados.

Apesar da sua importância, o governo brasileiro não dispõe atualmente dessa informação. Por se concentrar nos fluxos de caixa, as informações atualmente geradas pela contabilidade pública indicam quanto foi gasto em um determinado programa em um dado período, por exemplo, um ano, mas não o seu real custo. Para aferir o custo é necessário saber, por exemplo, o valor dos materiais empregados na prestação dos serviços (medicamentos e outros no caso da saúde), a depreciação de equipamentos e instalações, o custo do pessoal empregado, inclusive os encargos previdenciários, e demais gastos com o funcionamento do órgão encarregado de prover os serviços, como energia e comunicações.

Para gerar as informaçōes que permitem aferir os custos do governo é preciso que o setor público adote a contabilidade de competência utilizada no setor privado. Por esse regime, as informações financeiras são apropriadas quando o fato ocorre e não quando o desembolso é efetivado. Por exemplo, na apuração dos custos dos serviços de saúde em um dado ano, a parcela relativa a medicamentos inclui o valor de medicamentos adquiridos no ano anterior e consumidos no ano corrente, mais a parcela de medicamentos adquiridos e consumidos no mesmo ano, valor que obviamente difere das despesas realizadas com a aquisição de medicamentos no ano corrente.

Fonte: Rezende, Cunha e Bevilacqua (2010, p. 964)

Quanto à adoção da contabilidade por competência, Rezende, Cunha e Bevilacqua (2010, p. 965) afirmaram:

Sem a adoção da contabilidade por competência é impossível avançar na implantação de uma reforma na gestão pública que tenha por foco aumentar o valor dos recursos aplicados pelo governo e, portanto, ampliar o benefício social da tributação.

\section{Os mesmos pesquisadores identificaram também que:}

[...] entre países que avançaram na adoção da contabilidade de competência no setor público, as motivações diferem quanto ao uso a ser dado às informações geradas por esse regime, onde em alguns casos, a adoção da contabilidade de competência foi parte de uma reforma abrangente na administração pública, voltada para promover a eficiência das organizações governamentais, mediante a utilização de métodos de gestão semelhantes aos adotados por organizações privadas. (Rezende, Cunha \& Bevilacqua, 2010, p. 965)

Em relação às motivações para adoção de sistemas de custos em diferentes países, Rezende, Cunha e Bevilacqua (2010) apontaram as seguintes motivações, de acordo com o Quadro 2:

Quadro 2: Adoção de sistemas de custos em diferentes países: motivações

Sistemas de custos adotados como parte de uma ampla reforma voltada para o aumento da eficiência na gestão pública mediante introdução de competição na provisão de serviços e adoção de métodos privados de gestão

Austrália, Nova Zelândia e Reino Unido são os países em que essa motivação predominou. Nesse caso, a adoção da contabilidade de competência é vista como uma etapa no caminho do orçamento de competência.

Avaliação de riscos fiscais de longo prazo

Adoção da contabilidade de competência é importante para gerar informações que permitam avaliar riscos fiscais de longo prazo. Na Islândia, essa foi a principal motivação para adotar esse regime e conter a expansão dos gastos previdenciários. Essa também é uma preocupação importante nos Estados Unidos, principalmente agora com a adoção de medidas para combater a crise econômica.

Eficiência do Estado e melhoria da qualidade do gasto

Holanda e Canadá, que estiveram entre os pioneiros na adoção da contabilidade de competência, deram mais ênfase à contribuição da contabilidade de competência para a eficiência do Estado e à adoção de reformas voltadas para a privatização e a devolução de maiores responsabilidades na provisão de serviços a governos locais, mediante a descentralização fiscal.

Qualidade, transparência e confiabilidade das informações sobre as contas públicas

Essa foi uma motivação importante na França, que privilegiou a contribuição da contabilidade de competência para o controle interno e externo do Estado. 
Os autores ainda explicam que, "na maioria das experiências de adoção de sistemas de custos, os governos locais precederam o governo central no que diz respeito à adoção da contabilidade de competência" (Rezende, Cunha \& Bevilacqua, 2010, p. 991).

No Brasil, a iniciativa do Governo Federal de implantar um Sistema de Informação de Custos ocorreu em março de 2010, nasceu a partir da criação da Comissão Interministerial de Custos, por meio da Portaria MFAZ n॰ 945, em 2005, com o objetivo de elaborar estudos e propor diretrizes, métodos e procedimentos para subsidiar a implantação de Sistemas de Custos na Administração Pública Federal, o qual foi desenvolvido a partir dos estudos de doutoramento realizados por Machado (2002) e por Holanda (2002).

Partindo do pressuposto de que o fato gerador da despesa ocorre na fase da liquidação, e considerando-se que, conforme tratado na Lei no. 4.320,64, é nesta fase que se gera o direito do credor, o modelo proposto pelo Governo Federal sugere que, na ausência da contabilidade por regime de competência, utilize-se a informação orçamentária liquidada como fonte de alimentação do SIC, respeitados os ajustes propostos no modelo.

Segundo Machado e Holanda (2010, p. 805), o ajuste inicial do modelo utilizado pelo Governo Federal "consistiu na identificação e carregamento de informações [...] que trazem a informação orçamentária e não orçamentária, ajustando-se por acréscimo os valores orçamentários que não são custos do período". A segunda etapa de ajuste consiste na "exclusão de informações orçamentárias que não devem integrar a informação de custos" (Machado \& Holanda, 2010, p. 805), conforme Quadro 3:

Quadro 3: Modelagem dos ajustes conceituais

\begin{tabular}{|c|c|}
\hline \multicolumn{2}{|c|}{ Despesa orçamentária executada } \\
\hline & $\begin{array}{c}\text { Despesa liquidada }+ \\
\text { Despesa executada por inscrição de restos a pagar não processados }\end{array}$ \\
\hline \multicolumn{2}{|c|}{ Ajustes da despesa orçamentária } \\
\hline$(-)$ & Despesa executada por inscrição de restos a pagar não processados \\
\hline$(-)$ & Restos a pagar não processados liquidados no exerćício \\
\hline$(-)$ & Despesas de exercícios anteriores \\
\hline$(-)$ & Formação de estoques \\
\hline$(-)$ & Concessão de adiantamentos \\
\hline & Despesas de capital não efetivas \\
\hline$(+)$ & Ajustes patrimonial \\
\hline$(+)$ & Consumo de estoque \\
\hline$(+)$ & Despesa incorrida de adiantamentos \\
\hline$(=)$ Custo & Depreciação/amortização/exaustão \\
\hline
\end{tabular}

Fonte: Coordenação-geral de Contabilidade da União, Secretaria do Tesouro Nacional, adaptado por Machado e Holanda (2010, p.806).

Os ajustes propostos no modelo de SIC adotado pelo governo federal se fazem necessários, considerando que as informações primárias que alimentam o referido sistema são de natureza orçamentária, desta forma necessitando de ajustes (inclusões e exclusões de valores) para que se tornem equivalentes a informação de custos.

\subsection{REGIME CONTÁBIL ADOTADO NO SETOR PÚBLICO NO BRASIL}

No que tange às práticas internacionais, a Federação Internacional de Contadores (IFAC) publicou, em janeiro de 2010, o Manual de Pronunciamentos Internacionais de Contabilidade do Setor Público, 
tendo estabelecido nas IPSAS 1 (Internacional Public Sector Accounting Standards) "os requisitos mínimos gerais para apresentação de demonstrações contábeis elaboradas sob o regime de competência" (IFAC; CFC, 2010, p. 37).

No Brasil, a Lei n. 4.320, editada desde 1964, trata no Capítulo III do Título IX sobre a Contabilidade Patrimonial e Industrial, tendo estabelecido no artigo 100 o seguinte:

As alterações da situação líquida patrimonial, que abrangem os resultados da execução orçamentária, bem como as variações independentes dessa execução e as superveniências e insubsistência ativas e passivas, constituirão elementos da conta patrimonial.

Quanto à definição normativa que trata especificamente sobre regime contábil adotado pelo Setor Público no Brasil, foi editada em 2007 a Resolução n. 1.111/2007 do CFC, a qual aprovou o apêndice II da Resolução n. 750/93 do CFC - norma geral que dispõe sobre os Princípios de Contabilidade dando interpretação sob a perspectiva do setor público, em que, acerca do princípio da competência, foi apresentado o entendimento tratado no Quadro 4:

Quadro 4: Princípio da Competência sob a Perspectiva do Setor Público no Brasil

\begin{tabular}{|l|l|}
\hline $\begin{array}{l}\text { Princípio da Competência segundo a Norma Geral de } \\
\text { Contabilidade no Brasil (Resolução n०.750/93). }\end{array}$ & $\begin{array}{l}\text { Interpretação sob a perspectiva do Setor } \\
\text { Público }\end{array}$ \\
\hline $\begin{array}{l}\text { Art. } 9^{\circ} \text { O Princípio da Competência determina que os efeitos das } \\
\text { transações e outros eventos sejam reconhecidos nos períodos } \\
\text { a que se referem, independentemente do recebimento ou } \\
\text { pagamento. }\end{array}$ & \\
$\begin{array}{l}\text { Parágrafo único. O Princípio da Competência pressupõe a } \\
\text { simultaneidade da confrontação de receitas e de despesas } \\
\text { correlatas. }\end{array}$ & $\begin{array}{l}\text { O Princípio da Competência aplica-se } \\
\text { integralmente ao Setor Público }\end{array}$ \\
\hline
\end{tabular}

Fonte: Resolução CFC nº.1.111/2007.

Corroborando a definição prevista na Resolução no. 1.111/2007 que define a adoção do regime de competência para o reconhecimento das transações contábeis ocorridas no setor público, a NBC TSP 16.5 - Registro Contábil, publicada através da 1.132/2008, dispõe sobre o reconhecimento das transações no setor público da seguinte forma:

As transações no setor público devem ser reconhecidas e registradas integralmente no momento em que ocorrerem.

Os registros contábeis devem ser realizados e os seus efeitos evidenciados nas demonstrações contábeis do período com os quais de relacionam, reconhecidos, portanto, pelos respectivos fatos geradores, independentemente do momento da execução orçamentária.

Conforme tratado no parágrafo anterior, as Normas Brasileiras de Contabilidade Aplicadas ao Setor Público, em especial as Resoluções no. 1.111/2007 e nº 1.132/08 definem que o regime contábil a ser adotado pelas entidades do setor público para registros das transações contábeis patrimoniais deve ser o de competência.

Ressalta-se que, durante muitos anos, a contabilidade do orçamento fundamentada no disposto no artigo 35 da Lei no. 4.320/64 foi confundida com a contabilidade patrimonial, tratada também na referida Lei no artigo 100, cujo objeto de estudo é o patrimônio e sobre a qual os registros devem observar os princípios e normas brasileiras de contabilidade aplicadas ao setor público.

Buscando compatibilizar tais situações, a STN, ao emitir o MCASP, tratou separadamente sobre os procedimentos a serem observados pelas entidades do setor público no que tange aos Procedimentos Contábeis Orçamentários (Parte I - MCASP) e aos Procedimentos Contábeis Patrimoniais (Parte II - MCASP).

Por fim, salienta-se que o enfoque contábil tratado nesta pesquisa será o patrimonial, o qual deve observar os princípios contábeis e as normas brasileiras e internacionais de contabilidade aplicadas 
ao setor público. Portanto, deve registrar as variações patrimoniais que afetam o patrimônio de forma completa e no momento em que ocorrerem, independentemente do recebimento ou pagamento, ou seja, pelo princípio da competência contábil.

\section{PROPOSTA DE DIRETRIZES E METODOLOGIA PARA IMPLAN- TAÇÃO DE SUBSISTEMA DE MENSURAÇÃO E ACUMULAÇÃO DE CUSTOS NO SETOR PÚBLICO A PARTIR DAS INFORMAÇÕES PATRI- MONIAIS}

As entidades do setor público, são constituídas sob o pressuposto da continuidade, assim como o são as entidades de fins lucrativos. A plenitude dessa assertiva só é obtida quando os programas de governos e políticas, estabelecidos nas ferramentas de planejamento do Ente público, sejam executados, sob à égide da eficiência e eficácia, e, principalmente, produzam impactos positivos às demandas da sociedade receptadora do benefício (efetividade).

Neste sentido, o modelo de sistema de informações de custos para o setor público, desenvolvido por Machado (2002), foi de extrema importância no processo de geração de tais informações, tendo contribuído para a adoção do SIC na administração pública federal.

Entretanto, conforme Bevilacqua, Cunha e Rezende (2010, p.962), quando afirmam:

Para medir os custos, é preciso conhecer os recursos efetivamente consumidos na provisão de um determinado bem ou serviço, em um dado período, assim como a decorrente variação do ativo e do passivo governamental ocorrida no mesmo período, informações geradas pela contabilidade de competência (accrual accounting) adotada no setor privado.

Para Machado e Holanda (2010, p. 815), a metodologia de mensuração de custos utilizada pelo Governo Federal "convive ainda com as limitações atuais na contabilidade pública, a falta de integração dos sistemas estruturantes e a falta de padronização das estruturas organizacionais do Governo Federal". Entretanto, com a adoção da contabilidade patrimonial no setor público essa metodologia irá "gradativamente se aperfeiçoando".

O presente trabalho, a partir da revisão da escassa bibliografia existente em consonância com a experiência prática, profissional e acadêmica dos autores, o artigo tem como escopo apresentar contribuições as diretrizes e metodologia que auxiliem os gestores do setor público no processo de mensuração, apuração e evidenciação de informações gerenciais dos custos dos serviços e bens públicos.

Sob esta ótica, os sistemas de informações de custos devem contribuir para a efetividade das ações sob a responsabilidade dos gestores públicos, que deverão assegurar resultados e/ou benefícios positivos à coletividade de sua jurisdição.

Por conta dessas prerrogativas, a implantação do modelo proposto, só se justifica se atendidas as seguintes premissas:

a) a administração pública é constituída sob o pressuposto da continuidade dos seus serviços públicos;

b) a administração pública deve ser vista como um sistema aberto e dinâmico;

c) o programa de governo, por ser o instrumento de organização da atuação governamental no Brasil, deve refletir a eficiência, a eficácia e a efetividade do gestor público;

d) o gestor público, na busca da eficiência, eficácia e efetividade de gestão, deverá escolher a melhor alternativa dentre aquelas possíveis de execução em um programa de governo; 
e) os custos apurados devem manter a comparabilidade ao longo do tempo;

f) a responsabilidade de gestão é mensurada por cada ação do programa de governo: cada gestor tem autoridade e responsabilidade para aplicar os recursos colocados à sua disposição;

g) o gestor público é competente e empreendedor para planejar e executar os programas de governo.

h) Os registros contábeis devem atender, integral, os Princípios Contábeis sob a perspectiva do setor público, disciplinados na Resolução CFC no 1.111/2007, e as Normas Brasileiras de Contabilidade Aplicada ao Setor Público, em especial a NBC TSP 16.11 - Subsistema de Informação de Custos do Setor Público, editada pela Resolução CFC no 1.366/2011, e dos estudos anteriores que tratam sobre a questão.

i) Estas premissas representam o quadro de referência, que fundamenta, delimita e direciona o raciocínio lógico e conceitual que dão sustentação ao desenvolvimento do modelo proposto por este estudo.

\subsection{REQUISITOS}

De acordo com a NBC TSP 16.11, o processo de construção do sistema deve observar os seguintes requisitos (CFC, 2012):

- estar integrado com os objetivos organizacionais pretendidos, os processos decisórios que usarão as informações de custos segmentados por seus diferentes grupos de usuários, bem como os critérios de transparência e controle social.

- observar as etapas de identificação dos Objetos de Custos, identificação dos custos diretos, alocação dos custos diretos aos Objetos de Custos; evidenciação dos custos diretos dentro da classe de objetos definidos, identificação dos custos indiretos;

- capturar as informações dos demais sistemas de informações da entidade;

- observar os princípios e normas de contabilidade aplicada ao setor público, para fins de mensuração das informações patrimoniais;

- disponibilizar informações de custos por objeto para fins de análise e gestão de custos, com vistas a atender aos requisitos de transparência e prestação de contas, bem como auxiliar no processo gerencial dos recursos públicos.

\subsection{INFORMAÇÕES DE SUPORTE}

Para que o sistema seja viabilizado e se concretize de fato, é necessária a existência de processo sistematizado, que disponibilize corretamente as seguintes informações:

- matriz de objetivos organizacionais;

- especificação e classificação dos Objetos de Custos a serem mensurados;

- identificação e classificação dos insumos consumidos no processo de fornecimento de serviços à sociedade pela entidade;

- identificação dos gestores responsáveis pelos centros de responsabilidade - centro de custo;

- informações patrimoniais dos insumos consumidos por Objeto de Custo.

\subsection{LIMITAÇÕES DO TRABALHO}

O presente trabalho apresenta como limitações: 
- Utilização do método do custeio direto, onde os parâmetros para distribuição dos custos indiretos não serão tratados, cabendo a entidade no processo de análise e gestão de custos definir a metodologia a ser utilizada para distribuição dos custos indiretos, caso seja relevante.

- O subsistema proposto não contemplará a etapa de análise e gestão de custos, a qual poderá ser realizada pela entidade por meio de ferramenta manual ou informatizada, que permita realizar diversas análises a partir da informação gerada pelo modelo.

- Considerando que o Subsistema de Informação de Custos no Setor Público, proposto pela NBC TSP 16.11, é prática recente que se encontra em processo de implantação, não foi possível testar a aplicabilidade prática do subsistema proposto por meio de estudo de caso concreto.

\subsection{ESTRUTURA DO SISTEMA}

A partir do arcabouço legal que trata sobre contabilidade aplicada ao setor público e sistema de informação de custos aplicado ao setor público, bem como dos modelos de sistemas de custos para este setor, propostos por Silva (1996) e Machado (2002), tratados no Capítulo 3, e pressupostos básicos citados no item 4.1, o subsistema ora proposto será construído de forma a mensurar os custos por objeto de custo com base na informação patrimonial, a qual será gerada pelos sistemas estruturantes e validada pelo sistema de contabilidade da entidade.

A Figura 1 fornece uma visão geral das diretrizes a serem implantadas, enfocando as etapas de estudos e planejamento e implantação de ações para adoção do sistema e, por conseguinte, a mensuração, acumulação e disponibilização de informações de custos por objeto, as quais poderão ser utilizadas para fins de análise e gestão de custos.

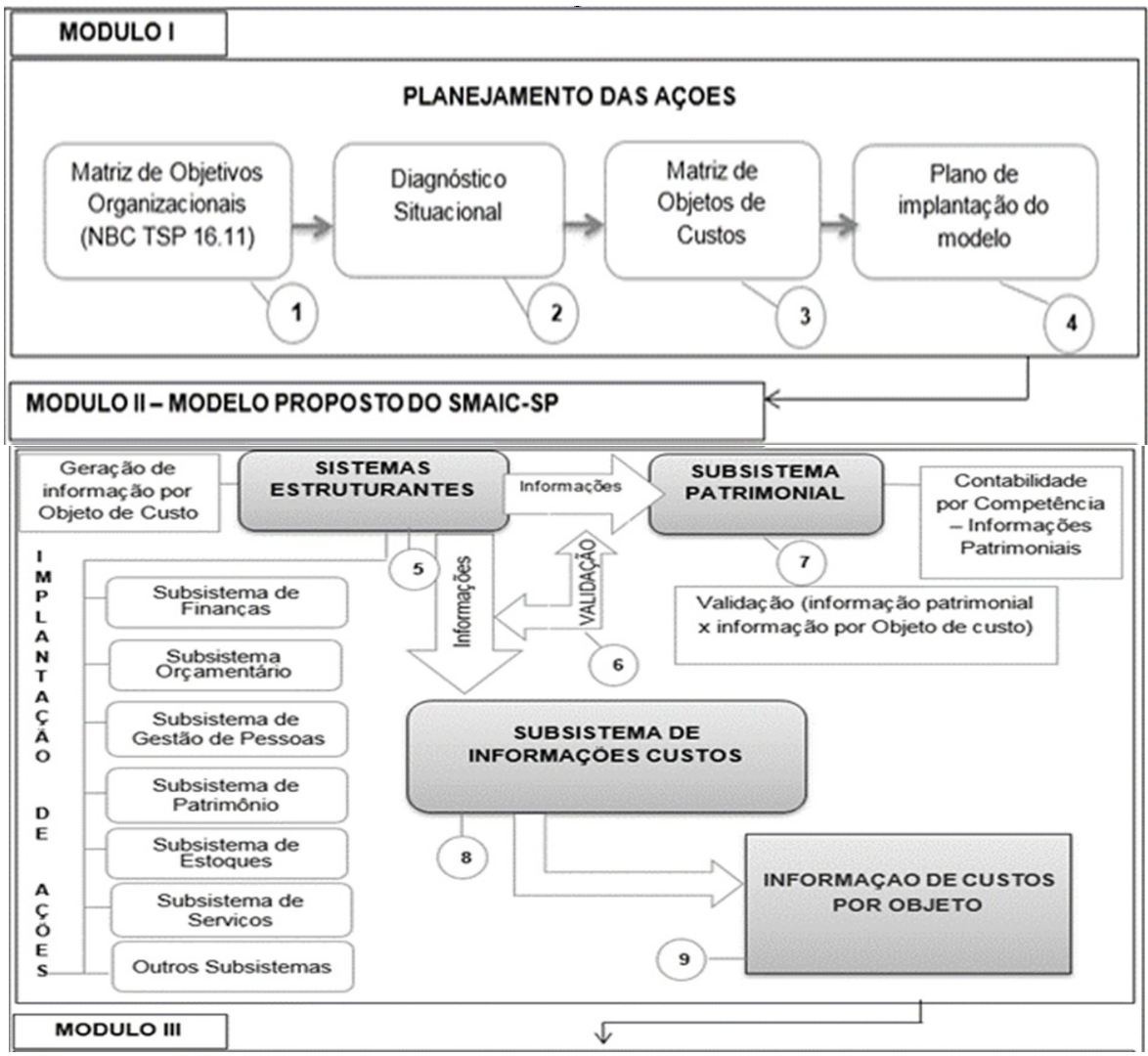




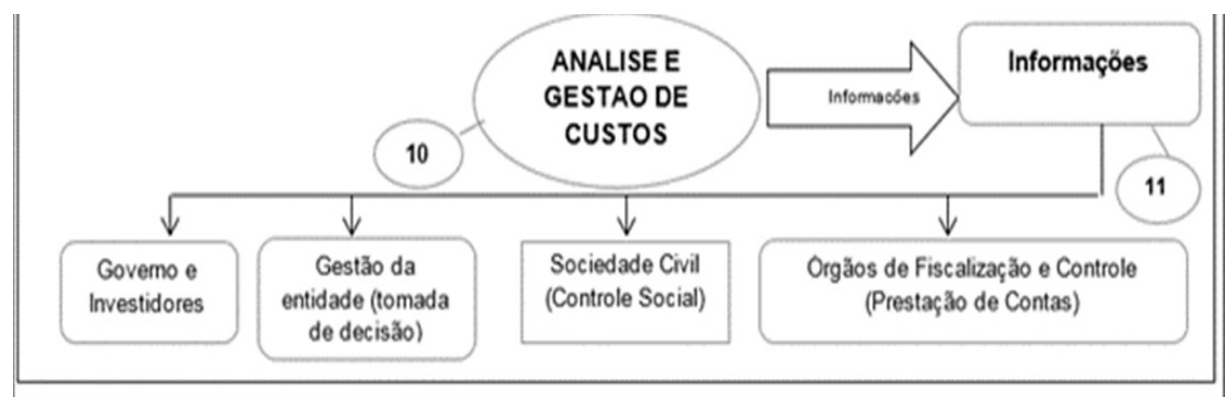

Figura 1: Visão Sistêmica do SMAIC-SP. Fonte: Elaborado pelos autores

Conforme evidenciado na Figura 1, o subsistema está estruturado em três módulos, entretanto, neste trabalho, só serão aprofundados apenas os Módulos I e ll, divididos por fases da forma que segue:

O Módulo I - aborda as fases de Estudos e Planejamento das Ações, as quais estão divididas nas seguintes fases:

1. Definição de matriz de objetivos organizacionais em atendimento ao disposto na NBC TSP 16.11;

2. Elaboração de diagnóstico da entidade;

3. Construção da matriz de objetos de custos;

4. Plano de implantação;

As fases de " 1 " a " 4 " representam o conjunto de ações que precedem a Implantação prática do SMAIC-SP, mas que são de extrema importância para o sucesso do projeto, pois irão definir os pressupostos básicos que irão nortear o processo de geração das informações para o Subsistema de Custos.

O Módulo II - trata dos procedimentos operacionais para Implantação das Ações, as quais estão divididas nas seguintes fases:

1. Controle dos bens e serviços consumidos na produção dos serviços disponibilizados à sociedade e concessão de informações patrimoniais do consumo por insumo e por objeto de custos;

2. Validação dos dados gerados pelos sistemas estruturantes acerca das informações patrimoniais por insumo e por objeto de custo;

3. Recebimento, processamento e geração (saída) de informações contábeis patrimoniais;

4. Recebimento, processamento e acumulação das informações patrimoniais aos seus respectivos objetos de custos, conforme matriz definida pela entidade;

5. Disponibilização (saída) das informações de custos por objeto conforme matriz definida pela entidade, a qual pode ser utilizada para fins de diversas análises e gestão de custos.

A fase " 5 " representa o processo de controle dos insumos consumidos na produção de bens e serviços oferecidos, bem como de geração de informações patrimoniais para alimentação dos subsistemas patrimonial e de mensuração e acumulação de custos.

A fase "6" representa o processo de validação das informações patrimoniais disponibilizadas, por insumo consumido e por objeto de custos, pelos sistemas estruturantes para fins de mensuração, registro e acumulação de custos.

As fases "7" e " 8 " representam o processo de entrada, processamento e saídas das informações patrimoniais mensuradas e reconhecidas pelos subsistemas, patrimonial e de custos.

A fase "9" representa a disponibilização de informações de custos por objeto, as quais poderão ser utilizadas para de fins prestação de contas, controle social, tomada de decisão e diversas análises de custos que podem ser realizadas pela entidade. 
Neste módulo inicia-se a implantação operacional do SMAIC-SP, onde são levantados, pelos sistemas estruturantes, as informações patrimoniais, por objeto de custo, que alimentam os subsistemas patrimonial e de informações de custos.

No subsistema proposto, o reconhecimento e acumulação dos custos, de determinado objeto, deverá ser devidamente registrado observando-se os princípios de contabilidade, as definições contidas nas Normas Brasileiras de Contabilidade e no Manual de Contabilidade Aplicada ao Setor Público.

A construção, operacionalização e manutenção do SMAIC-SP com base nas informações patrimoniais, ora proposto, requer a participação de no mínimo, dos setores da entidade que estão envolvidas no processo de gestão dos recursos, a exemplo da contabilidade, do controle interno, dos gestores dos centros de responsabilidade, dos controladores dos insumos e demais segmentos da entidade.

Conforme tratado pela NBC TSP 16.11 (CFC, 2011, p. 3), "é recomendável o uso de ferramentas que permitem acesso rápido aos dados, conjugado com tecnologias de banco de dados de forma a facilitar a criação de relatórios e a análise dos dados".

Nesse sentido, após registro, processamento e acumulação das informações de custos por objeto, ocorrerá a saída de informações do SMAIC-SP, as quais poderão ser utilizadas tanto para atendimento as suas finalidade básicas de prestação de contas, tomada de decisão e instrumentalização do controle social, bem como poderão ser utilizadas para fins de análise e gestão de custos de acordo com os parâmetros e necessidades identificados pela entidade. Considerando que o subsistema proposto visa definir apenas as diretrizes para implantação SMAIC-SP, o processo de análise de gestão de custos não será tratado de forma específica neste estudo. Isso poderá ser realizado por meio de diversos instrumentos de análise de dados, manuais, mecanizados ou informatizados de processamento de informações, a exemplo de planilhas Excel ou outras ferramentas equivalentes.

A partir das informações geradas pelo SMAIC-SP, o setor de análise e gestão de custos será responsável por gerar e evidenciar informações para os diversos usuários da informação de custos com vistas a atender o processo de tomada de decisão, da prestação de contas e da instrumentalização do controle social. De forma exemplificativa, apresenta-se a seguir, algumas análises que podem ser realizadas a partir das informações geradas pelo SMAIC-SP, conforme Tabelas 1 e 2:

Tabela 1: Informações de Custos Evidenciadas pelo SMAIC-SP

\begin{tabular}{|c|c|c|c|c|}
\hline Objeto de custo & Custo Orçado & Meta Física Orçada & Custo Histórico & Meta Física Realizada* \\
\hline 1. ÓRGÃO & $500.000,00$ & & $550.000,00$ & \\
\hline 1.1 Secretaria da Educação & $500.000,00$ & 4.000 & $550.000,00$ & 4.050 \\
\hline 2. FUNÇÃO & $500.000,00$ & & $550.000,00$ & \\
\hline 2.1 Educação & $420.000,00$ & 4.000 & $450.000,00$ & 4.050 \\
\hline 2.2 Administração & $80.000,00$ & 1 & $100.000,00$ & 1 \\
\hline 3. SUBFUNÇÃO & $500.000,00$ & & $550.000,00$ & \\
\hline 3.1 Ensino Fundamental & $170.000,00$ & 1.300 & $170.000,00$ & 1.250 \\
\hline 3.2 Ensino Infantil & $230.000,00$ & 2.700 & $230.000,00$ & 2.800 \\
\hline 3.3 Administração Geral & $100.000,00$ & 1 & $150.000,00$ & 1 \\
\hline 4. ESCOLA & $500.000,00$ & & $550.000,00$ & \\
\hline 4.1 Escola Viver Melhor & $115.000,00$ & 1.300 & $135.000,00$ & 1.310 \\
\hline 4.2 Escola Bom estudo & $130.000,00$ & 1.650 & $160.000,00$ & 1.700 \\
\hline 4.3 Escola Criança é Vida & $105.000,00$ & 1.050 & $105.000,00$ & 1.040 \\
\hline 4.4 Adm. Geral das Escolas & $150.000,00$ & 1 & $150.000,00$ & 1 \\
\hline
\end{tabular}

A partir das informações exemplificadas na Tabela 1, tomando-se como base o custeio direto, a entidade poderá fazer análise acerca dos custos por aluno e por escola, conforme pode-se observar na Tabela 2 a seguir: 
Tabela 2: Análise das Informações por Objeto de Custos

\begin{tabular}{|c|c|c|c|}
\hline Objeto de custo & $\begin{array}{c}\text { Quant. de Alunos } \\
\text { Atendidos }\end{array}$ & Custo Direto & $\begin{array}{c}\text { Custo por Aluno } \\
\text { (Unidade de Custo) }\end{array}$ \\
\hline 4. ESCOLA & 4.050 & $550.000,00$ & 135,80 \\
\hline 4.1 Escola Viver Melhor & 1.310 & $135.000,00$ & 103,05 \\
\hline 4.2 Escola Bom estudo & 1.700 & $160.000,00$ & 94,12 \\
\hline 4.3 Escola Criança é Vida & 1.040 & $105.000,00$ & 100,96 \\
\hline 4.4 Adm. Geral das Escolas & 4.050 & $150.000,00$ & 37,03 \\
\hline
\end{tabular}

Neste contexto, além das informações geradas pelo modelo proposto diversas análises podem ser geradas utilizando-se quantas variáveis forem necessárias a construção do processo de avaliação e gestão de custos, conforme modelo descrito: $U N-=x / y$, onde: $U N$ representa a unidade de custo; $x=$ custo por objeto; $y=$ variável de análises múltiplas.

Conforme demonstrado na equação acima, a identificação dos custos dos objetos de custos mensurados permitirá à entidade gerar diversas análises múltiplas, com vistas a produzir informações e relatórios que auxiliem o gestor público no processo de prestação de contas e tomada de decisão.

Entretanto, é preciso levar em conta que a efetivação das Normas Brasileiras de Contabilidade Aplicadas ao Setor Público no Brasil é recente e está em processo de implementação para se adequarem às disposições legais. Portanto, as entidades do setor público estão em processo de implantação dos procedimentos contábeis em observância aos princípios de contabilidade, em especial o de competência, por isso, não foi possível realizar um estudo de caso real para testar a aplicabilidade do subsistema proposto, onde, utilizou-se de um caso simulado pata testar a aplicabilidade do modelo.

\subsection{CASO SIMULADO}

Com a finalidade de testar a aplicabilidade do modelo, realizou um caso simulado envolvendo a Secretaria Municipal de Educação do Município de Mundo Alegre, a qual, no ano de 2013 tomou a decisão de adotar Projeto Piloto para implantar o SMAIC-SP, tanto para atendimento à exigência legal quanto para a geração de informações para tomada de decisão, dando início às ações apontadas no SMAIC-SP.

Depois de implantadas as fases de 1 a 7, o SMAIC-SP recebeu os dados enviados pelos sistemas estruturantes, identificou a competência e iniciou o registro e processamento, realizando o registro do custo orçado e a respectiva acumulação dos insumos consumidos aos respectivos objetos de custos (conforme matriz). Ambos com indicação das quantidades de bens e serviços estimados e realizados, as quais poderão ser controladas a partir do mecanismo da conta corrente contábil. Caso a entidade adote o modelo do Plano de Contas da Federação, proposto a título exemplificativo nesta pesquisa, tendo gerado as informações apresentadas nas Tabelas 3 e:

Tabela 3: Demonstrativo de contas do razão contábil - grupos 7.8 e 8.8 - SMAICP-SP - custo orçado a apurar

\begin{tabular}{|l|c|c|c|}
\hline \multicolumn{4}{|c|}{ Demonstrativo de Contas do Razão - Outubro/2013 - Custos Orçados a Apurar } \\
\hline \multicolumn{3}{|c|}{ Controle De Custos } & Natureza do Saldo \\
\hline Conta & Título & S & $2.059 .169,86$ \\
\hline 7.0 .0 .0 .0 .00 .00 & Controles Devedores & D & $2.059 .169,86$ \\
\hline 7.8 .0 .0 .0 .00 .00 & Custos & D & $2.059 .169,86$ \\
\hline 7.8 .1 .0 .0 .00 .00 & Custo Orçado & D & $906.516,95$ \\
\hline 7.8 .1 .1 .0 .00 .00 & Custos de Pessoal E Encargos & D & $177.690,68$ \\
\hline 7.8 .1 .2 .0 .00 .00 & Custos v Depreciação & D & $158.923,87$ \\
\hline 7.8 .1 .3 .0 .00 .00 & Custos de Uso De Material De Consumo & \\
\hline
\end{tabular}




\begin{tabular}{|c|c|c|c|}
\hline 7.8.1.4.0.00.00 & Custos de Serviços & $\mathrm{D}$ & $703.641,34$ \\
\hline 7.8.1.5.0.00.00 & Custos de Juros E Encargos & $\mathrm{D}$ & $112.397,03$ \\
\hline \multicolumn{4}{|c|}{ Apuração de Custos } \\
\hline 8.0.0.0.0.00.00 & Controles Credores & $\mathrm{C}$ & $2.059 .169,86$ \\
\hline $8.8 \cdot 0 \cdot 0 \cdot 0.00 .00$ & Apuração de Custos & C & $2.059 .169,86$ \\
\hline 8.8.1.0.0.00.00 & Custo a Realizar & $\mathrm{D}$ & $2.059 .169,86$ \\
\hline 8.8.1.1.0.00.00 & Secretaria de Educação & $\mathrm{C}$ & $2.059 .169,86$ \\
\hline 8.8.1.1.1.00.00 & Gabinete do Secretário de Educação & $\mathrm{C}$ & $479.323,00$ \\
\hline 8.8.1.1.1.01.00 & Educação & C & $322.236,00$ \\
\hline 8.8.1.1.1.01.01 & Administração Geral & $\mathrm{C}$ & $322.236,00$ \\
\hline 8.8.1.1.1.01.01.01 & Desenvolvimento da Secretaria de Educação & $\mathrm{C}$ & $322.236,00$ \\
\hline 8.8.1.1.1.01.01.01.01 & Manutenção das Ações da Secretaria & C & $322.236,00$ \\
\hline 8.8.1.1.1.02.00 & Encargos Especiais & $\mathrm{C}$ & $143.787,00$ \\
\hline 8.8.1.1.1.02.00 & Serviço da Dívida Interna & $\mathrm{C}$ & $143.787,00$ \\
\hline 8.8.1.1.1.02.01.01 & Desenvolvimento da Secretaria de Educação & $\mathrm{C}$ & $143.787,00$ \\
\hline 8.8.1.1.1.02.01.01.01 & Manutenção das Ações da Secretaria & $\mathrm{C}$ & $143.787,00$ \\
\hline 8.8.1.1.1.03.00 & Administração Geral do Gabinete & $\mathrm{C}$ & $13.300,00$ \\
\hline 8.8.1.1.2.00.00 & Fundo Municipal de Educação & $\mathrm{C}$ & $1.425 .365,26$ \\
\hline 8.8.1.1.2.01.00 & Educação & $\mathrm{C}$ & $1.425 .365,26$ \\
\hline 8.8.1.1.2.01.01 & Administração Geral & $\mathrm{C}$ & $115.435,00$ \\
\hline 8.8.1.1.2.01.02 & Ensino Fundamental & $\mathrm{C}$ & $607.883,76$ \\
\hline 8.8.1.1.2.01.02.01 & Desenvolvimento do Ensino Fundamental & C & $607.883,76$ \\
\hline 8.8.1.1.2.01.02.01.01 & Manutenção do Ensino Fundamental & C & $607.883,76$ \\
\hline 8.8.1.1.2.01.02.01.01.01 & $\begin{array}{c}\text { Centro Municipal de Arte, Cultura e } \\
\text { Educação Epifânia Silva }\end{array}$ & $\mathrm{C}$ & $230.706,72$ \\
\hline 8.8.1.1.2.01.02.01.01.02 & Escola Municipal Ana Nery & $\mathrm{C}$ & $190.783,10$ \\
\hline 8.8.1.1.2.01.02.01.01.03 & Escola Municipal Arte e Alegria & $\mathrm{C}$ & $137.568,94$ \\
\hline 8.8.1.1.2.01.02.01.01.04 & Adm. Geral Escolas - Ensino Fundamental & C & $48.825,00$ \\
\hline 8.8.1.1.2.01.03 & Ensino Infantil & $\mathrm{C}$ & $403.511,50$ \\
\hline 8.8.1.1.2.01.03.01 & Desenvolvimento do Ensino Infantil & $\mathrm{C}$ & $403.511,50$ \\
\hline 8.8.1.1.2.01.03.01.01 & Manutenção do Ensino Infantil & $\mathrm{C}$ & $403.511,50$ \\
\hline 8.8.1.1.2.01.03.01.01.01 & Escola Municipal Ana Nery & $\mathrm{C}$ & $205.087,50$ \\
\hline 8.8.1.1.2.01.03.01.01.02 & Escola Municipal Arte e Alegria & $\mathrm{C}$ & $177.054,00$ \\
\hline 8.8.1.1.2.01.03.01.01.03 & Adm. Geral Escolas - Ensino Infantil & $\mathrm{C}$ & $21.370,00$ \\
\hline 8.8.1.1.2.01.04 & Educação de Jovens e Adultos & $\mathrm{C}$ & $298.535,00$ \\
\hline 8.8.1.1.2.01.04.01 & $\begin{array}{l}\text { Desenvolvimento do Ensino de Jovens e } \\
\text { Adultos }\end{array}$ & $\mathrm{C}$ & $298.535,00$ \\
\hline 8.8.1.1.2.01.04.01.01 & Manutenção do Ensino de Jovens e Adultos & $\mathrm{C}$ & $298.535,00$ \\
\hline 8.8.1.1.2.01.04.01.01.01 & Escola Municipal Barão do Rio Branco & $\mathrm{C}$ & $153.860,00$ \\
\hline 8.8.1.1.2.01.04.01.01.03 & Escola Municipal do Pescador & $\mathrm{C}$ & $117.350,00$ \\
\hline 8.8.1.1.2.01.04.01.01.04 & Adm. Geral Escolas - EJA & $\mathrm{C}$ & $27.325,00$ \\
\hline $8.8 \cdot 1.1 .3 .00 .00$ & Administração Geral da Secretaria & $\mathrm{C}$ & $154.481,60$ \\
\hline
\end{tabular}

Tabela 2: Análise das Informações por Objeto de Custos

\begin{tabular}{|c|c|c|c|}
\hline \multicolumn{4}{|c|}{ Demonstrativo de Contas Do Razão - Outubro/2013 - Custos Apurados } \\
\hline \multicolumn{3}{|c|}{ Apuração de Custos } \\
\hline \multicolumn{5}{|c|}{ Tonta } & Titulo & $\begin{array}{c}\text { Natureza } \\
\text { do Saldo }\end{array}$ & Saldo \\
\hline 8.0 .0 .0 .0 .00 .00 & Controles Credores & D & $2.242 .978,96$ \\
\hline 8.8 .0 .0 .0 .00 .00 & Apuração de Custos & D & $2.242 .978,96$ \\
\hline 8.8 .1 .0 .0 .00 .00 & Custo a Realizar & D & $2.242 .978,96$ \\
\hline
\end{tabular}




\begin{tabular}{|c|c|c|c|}
\hline $8.8 .1 \cdot 1 \cdot 0.00 .00$ & Secretaria de Educação & $\mathrm{D}$ & $2.242 .978,96$ \\
\hline 8.8.1.1.1.00.00 & Gabinete do Secretário de Educação & $\mathrm{D}$ & $498.370,00$ \\
\hline $8.8 .1 \cdot 1.1 .01 .00$ & Educação & $\mathrm{D}$ & $327.440,00$ \\
\hline 8.8.1.1.1.01.01 & Administração Geral & $\mathrm{D}$ & $327.440,00$ \\
\hline 8.8.1.1.1.01.01.01 & Desenvolvimento da Secretaria de Educação & $\mathrm{D}$ & $327.440,00$ \\
\hline 8.8.1.1.1.01.01.01.01 & Manutenção das Ações Da Secretaria & $\mathrm{D}$ & $327.440,00$ \\
\hline 8.8 .1 .1 .1 .02 .00 & Encargos Especiais & $\mathrm{D}$ & $156.930,00$ \\
\hline 8.8.1.1.1.02.01 & Serviço da Dívida Interna & $\mathrm{D}$ & $156.930,00$ \\
\hline 8.8.1.1.1.02.01.01 & Desenvolvimento da Secretaria de Educação & $\mathrm{D}$ & $156.930,00$ \\
\hline 8.8.1.1.1.02.01.01.01 & Manutenção das Ações Da Secretaria & $\mathrm{D}$ & $156.930,00$ \\
\hline 8.8.1.1.1.03.00 & Administração Geral do Gabinete & $\mathrm{D}$ & $14.000,00$ \\
\hline 8.8.1.1.2.00.00 & Fundo Municipal de Educação & $\mathrm{D}$ & $1.551 .506,96$ \\
\hline 8.8.1.1.2.01.00 & Educação & $\mathrm{D}$ & $1.551 .506,96$ \\
\hline 8.8.1.1.2.01.01 & Administração Geral & $\mathrm{D}$ & $116.350,00$ \\
\hline 8.8.1.1.2.01.02 & Ensino Fundamental & $\mathrm{D}$ & $670.281,96$ \\
\hline $8.8 .1 \cdot 1 \cdot 2 \cdot 01.02 .01$ & Desenvolvimento do Ensino Fundamental & $\mathrm{D}$ & $670.281,96$ \\
\hline 8.8.1.1.2.01.02.01.01 & Manutenção do Ensino Fundamental & $\mathrm{D}$ & $670.281,96$ \\
\hline 8.8.1.1.2.01.02.01.01.01 & Centro Municipal de Arte, Cultura e Educação Epifânia Silva & $\mathrm{D}$ & $241.040,80$ \\
\hline 8.8.1.1.2.01.02.01.01.02 & Escola Municipal Ana Nery & $\mathrm{D}$ & $192.809,00$ \\
\hline 8.8.1.1.2.01.02.01.01.03 & Escola Municipal Arte e Alegria & $\mathrm{D}$ & $138.782,16$ \\
\hline 8.8.1.1.2.01.02.01.01.04 & Adm. Geral Escolas - Ensino Fundamental & $\mathrm{D}$ & $97.650,00$ \\
\hline 8.8.1.1.2.01.03 & Ensino Infantil & $\mathrm{D}$ & $435.325,00$ \\
\hline $8.8 .1 \cdot 1 \cdot 2 \cdot 01.03 .01$ & Desenvolvimento e o Ensino Infantil & $\mathrm{D}$ & $435.325,00$ \\
\hline 8.8 .1 .1 .2 .01 .03 .01 .01 & Manutenção e o Ensino Infantil & $\mathrm{D}$ & $435.325,00$ \\
\hline 8.8.1.1.2.01.03.01.01.01 & Escola Municipal Ana Nery & $\mathrm{D}$ & $213.425,00$ \\
\hline 8.8.1.1.2.01.03.01.01.02 & Escola Municipal Arte E Alegria & $\mathrm{D}$ & $179.160,00$ \\
\hline $8.8 .1 \cdot 1 \cdot 2.01 .03 .01 .01 .03$ & Adm. Geral Escolas - Ensino Infantil & $\mathrm{D}$ & $42.740,00$ \\
\hline 8.8.1.1.2.01.04 & Educação de Jovens e Adultos & $\mathrm{D}$ & $329.550,00$ \\
\hline $8.8 \cdot 1 \cdot 1 \cdot 2 \cdot 01 \cdot 04.01$ & Desenvolvimento do Ensino de Jovens e Adultos & $\mathrm{D}$ & $329.550,00$ \\
\hline 8.8.1.1.2.01.04.01.01 & Manutenção do Ensino de Jovens e Adultos & $\mathrm{D}$ & $329.550,00$ \\
\hline 8.8 .1 .1 .2 .01 .04 .01 .01 .01 & Escola Municipal Barão do Rio Branco & $\mathrm{D}$ & $158.300,00$ \\
\hline 8.8.1.1.2.01.04.01.01.03 & Escola Municipal do Pescador & $\mathrm{D}$ & $116.600,00$ \\
\hline 8.8.1.1.2.01.04.01.01.04 & Adm. Geral Escolas - EJA & $\mathrm{D}$ & $54.650,00$ \\
\hline $8.8 \cdot 1 \cdot 1 \cdot 3 \cdot 00.00$ & Administração Geral da Secretaria & $\mathrm{D}$ & $193.102,00$ \\
\hline 8.8.2.0.0.00.00 & Custo Realizado & C & $2.242 .978,96$ \\
\hline 8.8.2.1.0.00.00 & Secretaria de Educação & $C$ & $2.242 .978,96$ \\
\hline 8.8.2.1.1.00.00 & Gabinete do Secretário de Educação & C & $498.370,00$ \\
\hline 8.8.2.1.1.01.00 & Educação & $\mathrm{C}$ & $327.440,00$ \\
\hline 8.8.2.1.1.01.01 & Administração Geral & $\mathrm{C}$ & $327.440,00$ \\
\hline 8.8.2.1.1.01.01.01 & Desenvolvimento da Secretaria de Educação & $\mathrm{C}$ & $327.440,00$ \\
\hline 8.8.2.1.1.01.01.01.01 & Manutenção das Ações Da Secretaria & $\mathrm{C}$ & $327.440,00$ \\
\hline 8.8.2.1.1.02.00 & Encargos Especiais & C & $156.930,00$ \\
\hline 8.8.2.1.1.02.01 & Serviço da Dívida Interna & $\mathrm{C}$ & $156.930,00$ \\
\hline 8.8.2.1.1.02.01.01 & Desenvolvimento da Secretaria de Educação & C & $156.930,00$ \\
\hline 8.8 .2 .1 .1 .02 .01 .01 .01 & Manutenção das Ações Da Secretaria & C & $156.930,00$ \\
\hline 8.8.2.1.1.03.00 & Administração Geral do Gabinete & $\mathrm{C}$ & $14.000,00$ \\
\hline $8.8 \cdot 2 \cdot 1 \cdot 2 \cdot 00.00$ & Fundo Municipal de Educação & C & $1.551 .506,96$ \\
\hline 8.8.2.1.2.01.00 & Educação & C & $1.551 .506,96$ \\
\hline $8.8 .2 \cdot 1 \cdot 2 \cdot 01.01$ & Administração Geral & C & $116.350,00$ \\
\hline 8.8.2.1.2.01.02 & Ensino Fundamental & C & $670.281,96$ \\
\hline
\end{tabular}




\begin{tabular}{|c|c|c|c|}
\hline 8.8.2.1.2.01.02.01 & Desenvolvimento do Ensino Fundamental & $\mathrm{C}$ & $670.281,96$ \\
\hline 8.8.2.1.2.01.02.01.01 & Manutenção do Ensino Fundamental & C & $670.281,96$ \\
\hline 8.8.2.1.2.01.02.01.01.01 & Centro Municipal de Arte, Cultura e Educação Epifânia Silva & $\mathrm{C}$ & $241.040,80$ \\
\hline 8.8.2.1.2.01.02.01.01.02 & Escola Municipal Ana Nery & $\mathrm{C}$ & $192.809,00$ \\
\hline 8.8.2.1.2.01.02.01.01.03 & Escola Municipal Arte e Alegria & $\mathrm{C}$ & $138.782,16$ \\
\hline 8.8.2.1.2.01.02.01.01.04 & Adm. Geral Escolas - Ensino Fundamental & $\mathrm{C}$ & $97.650,00$ \\
\hline 8.8.2.1.2.01.03 & Ensino Infantil & $\mathrm{C}$ & $435.325,00$ \\
\hline 8.8.2.1.2.01.03.01 & Desenvolvimento e o Ensino Infantil & $\mathrm{C}$ & $435.325,00$ \\
\hline 8.8.2.1.2.01.03.01.01 & Manutenção e o Ensino Infantil & C & $435.325,00$ \\
\hline 8.8.2.1.2.01.03.01.01.01 & Escola Municipal Ana Nery & C & $213.425,00$ \\
\hline 8.8.2.1.2.01.03.01.01.02 & Escola Municipal Arte e Alegria & C & $179.160,00$ \\
\hline 8.8.2.1.2.01.03.01.01.03 & Adm. Geral Escolas - Ensino Infantil & C & $42.740,00$ \\
\hline 8.8.2.1.2.01.04 & Educação de Jovens e Adultos & C & $329.550,00$ \\
\hline 8.8.2.1.2.01.04.01 & Desenvolvimento do Ensino de Jovens e Adultos & C & $329.550,00$ \\
\hline 8.8.2.1.2.01.04.01.01 & Manutenção do Ensino de Jovens e Adultos & C & $329.550,00$ \\
\hline 8.8.2.1.2.01.04.01.01.01 & Escola Municipal Barão do Rio Branco & C & $158.300,00$ \\
\hline 8.8.2.1.2.01.04.01.01.03 & Escola Municipal do Pescador & C & $116.600,00$ \\
\hline 8.8.2.1.2.01.04.01.01.04 & Adm. Geral Escolas - EJA & C & $54.650,00$ \\
\hline $8 \cdot 8 \cdot 2 \cdot 1 \cdot 3 \cdot 00.00$ & Administração Geral da Secretaria & $\mathrm{C}$ & $193.102,00$ \\
\hline
\end{tabular}

Após processamento e acumulação e análise das informações patrimoniais aos respectivos objetos de custo do exemplo simulado, em que pese às limitações da pesquisa, pode-se inferir que:

- O SMAIC-SP gera informações dos custos dos serviços prestados por objetos de custos, em observância aos princípios e normas de contabilidade aplicada ao setor público, especialmente a NBC TSP 16.11, desta forma, poderá contribuir com os gestores públicos no processo de implantação do SICSP.

- Observa-se também que as informações geradas pelo SMAIC-SP podem ser utilizadas pela entidade para fins de tomada de decisão, prestação de contas, instrumentalização do controle social.

- Identifica-se também que as informações de custos geradas pelo SMAIC-SP a partir das informações patrimoniais podem contribuir para o processo de análise e gestão de custos das entidades, permitindo a identificação dos custos dos objetos, dos quais se pretende controlar, mensurar e analisar para fins de avaliação de desempenho acerca da eficiência, eficácia e efetividade das ações realizadas pela entidade, sendo então possível realizar várias inferências e análises, conforme exemplo abaixo o qual demonstra o custo por Objeto - Subfunção de Governo:

Tabela 5: Custo por Aluno por Subfunção de Governo

\begin{tabular}{|c|c|c|c|}
\hline Subfunção & $\begin{array}{c}\text { Quantidade de Alunos } \\
\text { Atendidos }\end{array}$ & Custo Realizado & Custo por Aluno \\
\hline Ensino Fundamental & 2.233 & $670.281,96$ & 300,17 \\
\hline Ensino Infantil & 1.335 & $435.325,00$ & 326,09 \\
\hline Educação De Jovens E Adultos & 462 & $329.550,00$ & 713,31 \\
\hline Administração Geral & 4.030 & $650.892,00$ & 161,51 \\
\hline Serviços Da Dívida & 4.030 & 156.930 .00 & 38,94 \\
\hline TOTAL & 4.030 & $2.242 .978,96$ & 556,57 \\
\hline
\end{tabular}

Por fim, salienta-se que a entidade pode definir outras metodologias para reconhecimento, acumulação e evidenciação das informações de custos, além do exemplo trabalhado nesta pesquisa, a qual utilizou o Plano de Contas da Federação, permitindo desta forma uma maior flexibilização quando da ocorrência de mudanças da matriz de objeto de custo. 


\section{CONSIDERAÇÕES FINAIS}

O desenvolvimento da presente pesquisa foi orientado com base no problema objeto de pesquisa, de como estruturar um conjunto de diretrizes para implantação de Subsistema de Mensuração e Acumulação de Informações de Custos dos Serviços Públicos que atenda aos Princípios Contábeis e às orientações contidas nas Normas Brasileiras de Contabilidade Aplicadas ao Setor Público, em especial à NBC TSP 16.11 .

A partir do problema proposto, foi concebido o objetivo geral, que teve como propósito estabelecer um conjunto de diretrizes de abrangência geral a ser aplicado nas três esferas de governo: União, Estados (incluindo o Distrito Federal) e Municípios, que auxilie os gestores públicos no processo de implantação de um subsistema de mensuração e acumulação de informações de custos dos serviços públicos (SMAIC-SP), objetivando identificar os custos dos serviços por objetos de custos de acordo com as necessidades legais e gerenciais das entidades do setor público, com o objetivo de contribuir com o processo de prestação de contas, tomada de decisão de instrumentalização do controle social pelo cidadão.

Após aplicação de caso simulado, a partir do subsistema proposto, pode-se inferir que o SMAIC-SP pode auxiliar no processo de geração de informação de custos por objetos de custos. Em atendimento aos princípios e normas de contabilidade aplicados ao setor público e em conformidade com o disposto pela NBC TSP 16.11, desta forma, contribuindo com as entidades públicas no processo de implantação do SICSP. Observa-se ainda que as informações de custos geradas pelo SMAIC-SP podem contribuir para o processo de prestação de contas, tomada de decisão e instrumentalização do controle social, bem como servir de apoio ao processo de gestão e análise de custos. Desta forma gerar informações tanto do ponto de vista legal, quanto gerencial que podem auxiliar os gestores públicos na administração dos recursos públicos.

O subsistema é, portanto, no que pese as limitações indicadas no tópico 4.4, é uma ferramenta conceitual, operacional e tecnológica que poderá contribuir no processo de implantação do SICSP pelas entidades do setor público. Pretende-se, portanto, que o SMAIC-SP seja submetido à apreciação das autoridades competentes - especialmente ao Governo Federal, Estaduais, Prefeituras Municipais, Órgãos Legislativos e Tribunais de Contas - como contribuição ao processo de implantação de um Subsistema de Informações de Custos dos Serviços Públicos, em conformidade com a NBC TSP 16.11. De forma que este, em sendo aplicado, possa apoiar os gestores públicos no processo de implantação do SICSP.

Por fim, o SMAIC-SP proposto abre a perspectiva para futuras pesquisas na área de análise e gestão de custos, pois as informações geradas pelo SMAIC-SP permitirão a realização de diversas análises a partir da utilização de variáveis múltiplas com vistas a desenvolver indicadores de custos e de desempenho tanto para fins gerenciais quanto para transparência e prestação de contas. 
Conselho Federal de Contabilidade (CFC). (2012). Normas brasileiras de contabilidade: contabilidade aplicada ao setor público: NBCs T 16.1 a 16.11. Brasília, DF: Conselho Federal de Contabilidade, 2012. (Resoluções no. 1.128 a 1366.) Disponível em: <http://portalcfc.org.br/wordpress/wp-content/uploads/2013/01/Setor_P\%C3\%BAblico.pdf>. Acesso em: 05 jul. 2013.

Conselho Federal de Contabilidade (CFC). Resolução n. 1111, de 29 de novembro de 2007. Aprova o Apêndice Il da Resolução CFC n. 750/93 sobre os Princípios de Contabilidade. Diário Oficial da União, Brasília, DF, 05 dez. 2007.

Cruvinel, Daniel P \& Lima, Diana V. (2011). Adoção do regime de competência no setor público Brasileiro sob a perspectiva das normas Brasileiras e internacionais de contabilidade. Revista de Educação e Pesquisa em Contabilidade, Brasília, (5)3: art. 4, pp. 69-85, set-dez. 2011. Disponível em: <http://www. repec.org.br/index.php/repec/article/view/185/360>. Acesso em: 05 jul. 2013.

Fernandes, Júlio Cesar de Campos \& Slomski, Valmor. (2011). A gestão de Custos no Contexto da Qualidade no serviço público: um estudo entre organizações Brasileiras. In: Congresso Usp de Iniciação Científica em Contabilidade, 8., 2011, São Paulo. Anais... São Paulo: USP. Disponível em: <http://www. congressousp.fipecafi.org/artigos112011 /473.pdf>. Acesso em: 03 jul. 2013.

Holanda, Victor Branco. (2002). Controladoria governamental no contexto do governo Eletrônico: uma modelagem utilizando o enfoque sistêmico e a pesquisa-ação na Coordenadoria de Controle Interno da Secretaria da Fazenda do Estado de São Paulo. 2002. Tese (Doutorado em Controladoria e Contabilidade) - Programa de Pós-Graduação em Controladoria e Contabilidade, Universidade de São Paulo.

International Federation of Accountants (IFAC) \& Conselho Federal de Contabilidade (CFC). (2010). Normas Internacionais de Contabilidade para o setor público - IPSAS. Brasília, DF: Conselho Federal de Contabilidade. Disponível em: <http://portalcfc.org.br/wordpress/wp-content/uploads/2013/01/ ipsas2010_web.pdf>. Acesso em: 05 jul. 2013.

Machado, Nelson. (2002). Sistema de Informação de Custo: Diretrizes para integração ao orçamento público e à contabilidade governamental. 233 f. Tese (Doutorado em Controladoria e Contabilidade) Faculdade de Economia, Administração e Contabilidade da Universidade de São Paulo.

Machado, Nelson \& Holanda, Victor Branco de. (2010). Diretrizes e modelo conceitual de custos para o setor público a partir da experiência no Governo Federal do Brasil. Revista de Administração Pública RAP, Rio de Janeiro, 44(4): pp. 791-820, jul.-ago. 2010. Disponível em: <http://www.scielo.br/pdf/rap/ v44n4/v44n4a03.pdf>. Acesso em: 03 jul. 2013.

Reis, Luciano Gomes de, Ribeiro, Priscila Andreoni \& Slomski, Valmor. (2005). Custos no setor público: uma proposta de implementação de sistemas de custeio. In: IX Congresso Internacional de Custos Florianópolis, SC, Brasil, 11, Florianópolis. Anais... Florianópolis. Disponível em:<http://www.intercostos. org/documentos/custos_302.pdf>. Acesso em: 02 jul. 2015.

Rezende, Fernando, Cunha, Armando \& Bevilacqua, Roberto. (2010). Informações de custos e qualidade do gasto público: lições da experiência internacional. Revista de Administração Pública, Rio de Janeiro, (44)4: jul.-ago. Disponível em: <http://www.scielo.br/pdf/rap/v44n4/v44n4a09.pdf>. Acesso em: 03 jul. 2013.

Silva, Lino Martins. (1996). Contribuição ao estudo para implantação de um sistema de custeamento na administração pública. Tese (Livre Docência). Rio de Janeiro: Universidade Gama Filho. 